\title{
Practical Approaches Toward Sustainable Development in Iranian Green Construction
}

\author{
M.R. Darabpour a, M. Darabpour ${ }^{\text {b }}$, J. Majrouhi Sardroud ${ }^{\mathrm{c}}$, G. Tabarsa ${ }^{\mathrm{d}}$, \\ J. Smallwood ${ }^{\mathrm{e}}$ \\ ${ }^{a}$ Ph.D. Candidate, Department of Civil Engineering, Central Tehran Branch, Islamic Azad University, Tehran, Iran . \\ ${ }^{b}$ Professor, Faculty of Law, Shahid Beheshti University, Tehran, Iran. \\ ${ }^{c}$ Assistant Professor, Department of Civil Engineering, Central Tehran Branch, Islamic Azad University, Tehran, Iran. \\ ${ }^{d}$ Professor, Faculty of Management and Accounting, Shahid Beheshti University, Tehran, Iran.
}

e Professor, Department of Construction Management, Nelson Mandela University, Summerstrand Campus (North), South Africa.

Received 25 July 2018; Accepted 05 October 2018

\begin{abstract}
Developed nations acknowledge sustainable development as a legal right for current and future generations. Although instances of domestic and international efforts are prevalent, there is a long way to go before accomplishing developmental ideals. A practical approach for realizing the vital goals of sustainable development is of the utmost importance. In effect, the construction sector requires extensive forward-looking studies for strategizing, building and granting a sustainable future. The inconsistency between the goals and activities of different sectors is a main impediment upon undertaking sustainable development's goals; decision and lawmakers must consider the purpose and interests of the building industry on a micro and macro level. This paper is a brief review for understanding the concept of sustainable development and illustrates some of the international efforts, and highlights them for decision makers. Using the 'PESTLE' analysis technique, external and internal factors influencing sustainability in the Iranian construction sector were identified. Interviews were conducted with experts using the 'Snowball' research method due to the lack of knowledgeable respondents in the subject area. 11 Practical steps needed in Iran were recommended and sorted by their importance to make this vision a reality. The results can be generalized to other disciplines as well.
\end{abstract}

Keywords: Sustainable Development; Sustainable Construction; PESTLE.

\section{Introduction}

Development is a well-recognized phenomenon and term for human society. However, sustainable development is a concept which has manifested itself in the past five decades. From the introduction of the sustainable development idea at the Stockholm conference in 1972 [1] until now, various ideas with regards to its essence and application have been proposed. Until four decades ago, development goals and their policies revolved around economic perspectives, and focused on income generation and economic return maximization. Nonetheless, towards the end of the twentieth century, for the sake of a better life than the current conditions and creation of idealistic conditions for future generations, development and growth moved towards growth on economic, cultural, industrial, and environmental aspects.

According to the first Article of the 'Rio' Manifesto, humans are pivotal in development [2]. All activities shall be

* Corresponding author: j.majrouhi@iauctb.ac.ir

dol http://dx.doi.org/10.28991/cej-03091172

$>$ This is an open access article under the CC-BY license (https://creativecommons.org/licenses/by/4.0/).

(C) Authors retain all copyrights. 
guided in a direction in which a healthy human can live and grow in a healthy environment; furthermore, the same conditions should be available for future generations.

The concept of sustainable development was introduced in Iran in 1994. In order to develop appropriate policies and to coordinate between the country's socio-economic plans, environmental protection goals and the achievements of 1992 Earth Summit in Rio, the government of the Islamic Republic of Iran has established 'A National Committee for Sustainable Development', whose members are the fully authorized representatives from different ministries and governmental and non-governmental organizations in the country [3].

From ancient times, development has meant improvement of the current situation to a better condition. However, it is believed that after the Second World War, in the developed countries which could accommodate the main needs of their society, the view on development changed and gained a wider consideration. Developed countries attempted to define idealistic economic goals by establishing committal rules and regulations even if it requires them to ask for aid from less developed countries. It could be argued that one of the main sustainable development policies of the developed countries was to use the natural resources of the less developed countries to sustain their own natural environment[4]. For example, even though many developed countries have many natural resources such as oil and iron, they are keen on importing such raw materials. Furthermore, they even show retraining on participation in industries which may require them to use their other natural resources such as water, and thus they try to establish these industries in less developed countries.

There is no concrete and absolute definition for sustainable development, thus each organization and institution has defined the term based on their own agenda and goals. The term sustainable development was first introduced in the 1986 international convention in the report titled 'Our Common Future'. The 1987 Brundtland Convention defined sustainable development as "meeting the needs of the present generation without compromising the ability of future generations to meet their own needs" [5]. The Brundtland's report explains that "Sustainable development is collection of methods to create and sustain development which seeks to relieve poverty, create equitable standards of living, satisfy the basic needs of all peoples, and establish sustainable political practices all while taking the steps necessary to avoid irreversible damages to natural capital in the long term in turn for short term benefits by reconciling development project with the regenerative capacity of the natural environment".

There are several definitions and aims for sustainable development [6], however the common aspect between them all, can be summarized in two parts; first, development and betterment towards an appropriate acceptable situation for everyone. Secondly, maintaining an appropriate situation for future generations. Until now, the definitions seem clear, nonetheless the problem arises when the definition for appropriate and the limitation become unclear. It is unclear until what point does betterment is considered ideal. It is unclear that up to what point, maintaining of resources, especially natural resources, is required. It is also questioned that which is more important as a priority the current betterment or future betterment? Finally, the answer to the question that is the aim of the study: How to accomplish this in the construction sector.

Sustainability is considered one of the most significant challenges facing society today[7]. There currently exists no consensus on developmental components and indicators. One of the country's main development problems is an inconsistency between the goals and activities of different sectors. To undertake sustainable development's goals, decision makers must consider the purpose and interests of the building industry on a micro and macro level.

Expansion in any field inevitably requires continuity and endurance. Developed nations have currently acknowledged sustainable development as a legal right for current and future generations. Iran has also taken steps in this direction. But has a long way to go before accomplishing developmental ideals. The reason why is of utmost importance.

In effect, the construction sector requires extensive forward-looking studies for strategizing and building the future. Otherwise, using the resources of the future will not be possible. This paper has recommended practical approaches toward sustainable construction industry by considering the experts' opinion.

\section{Background: Sustainable Development and Green Constructions}

In this part of the paper, a brief explanation of the concept, components, aspirations, and indicators of sustainable development and sustainable construction are presented. Where necessary, Iranian efforts or issues, which need more attention by Iranian managers, engineers, and lawmakers have been illustrated.

\subsection{Components of Development}

Sustainability and development cannot be considered without considering the human factor and human decisions and related components at the core of this principle. The term 'development' is used in many disciplines and serves in practice to define a recognized field of research.

Today the complexity of effective indicators of development makes it harder to pinpoint and determine a confident 
factor. For every development scenario, three components play an essential role:

- Policy implementation and legal support;

- Betterment of scientific and technological management, and

- Betterment of education system and structure.

The connection between deciding centres and scientific executive centres is important for a sustainable development. Although, understanding the problem is half of the solution, currently, the main issue is not problem seeking, it has been long established what the world problem is. Many scientific centres research and published materials, which encapsulate the problems with sustainable development; however, these publications have no executive backing. These perspectives have not been collectively considered. Many different fields have come up with various proposals with regards to the sustainable development; such as law, management, economics, civil engineering, and architecture. However, it is yet to be resolved as to why this issue has remained unresolved.

\subsection{Pillars of Sustainable Development}

Sustainable development is a mixture of three major sections, Social development, economic development, and Environment[8]. Without considering any of these aspects, a true sustainable development may not be attained. In other words, sustainable development is a merging of social and economic Justice, and human understanding of usage of available resources with respect to future [9].
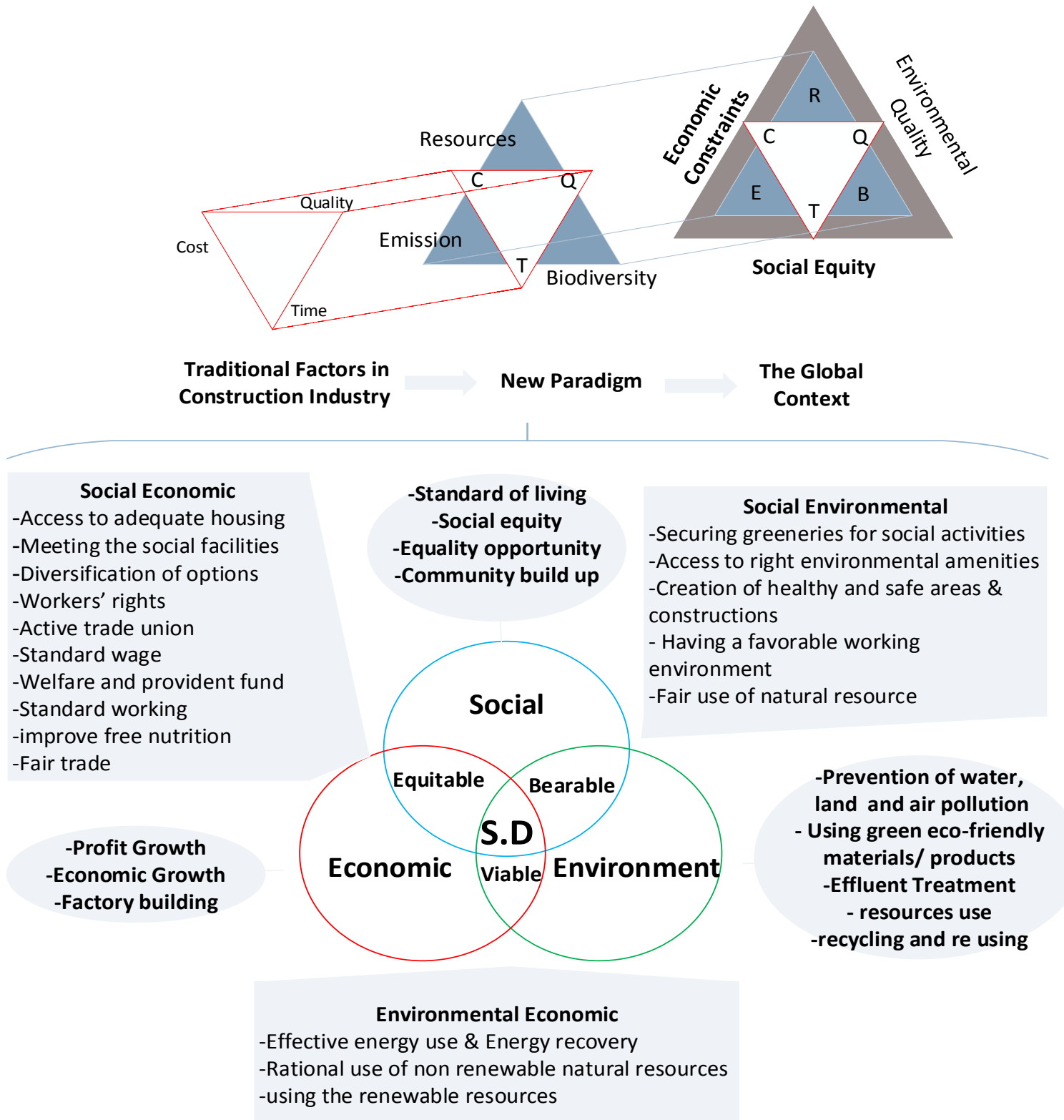

Figure 1. Requirements and pillars for sustainability, from the micro level to global level, including some significant dimensions that are being discussed in terms of a sustainable construction [10] 
In order, to give a bright view of how traditional engineering will be broadened when environmental demands are considered, a model was developed by the International Council of Research and Innovation in Building and Construction (CIB). Regarding this model, the economic and sociocultural issues are presented in the global context, together with the environmental issues. The comprehensive sustainable object, regardless of scale (city, neighborhood, or even a dwelling), can maintain a balance between these pillars. Many researchers have done sterling work in terms of identifying the internal and external effects derived from the interaction between the three major sections of sustainable development and have contributed to make sustainability a complicated idea. Figure 1 presents requirements and pillars for sustainability, from the micro level to the global level, including some significant dimensions that are being discussed in terms of sustainable construction that could bring a different view to engineering approaches during sustainable planning.

In addition to above, some authors recommend the inclusion of a fourth pillar of culture, institutions or governance, or alternatively reconfigured as four domains of the social - ecology, economics, politics and culture [11]. These researchers have argued that culture should be viewed, not just as the fourth pillar, but as the central pillar of sustainable development. They express that this comes from the interrogation and deconstruction of the meaning and practice of development itself and have tried to outline a framework for reconstructing the sustainable development agenda that has the potential for greater coherence with the goals and values such as social justice, self-reliance and ecological balance [12].

\subsection{Aspirations of Sustainable Development}

In a fight against poverty, inequality, climate change, the September 2015 New York Convention, introduced 17 new goals which aimed to provide a more sustainable developed world and ensuring a safer more prosperous world for future generations [13]. The 17 main goals are illustrated in Figure 2 below.
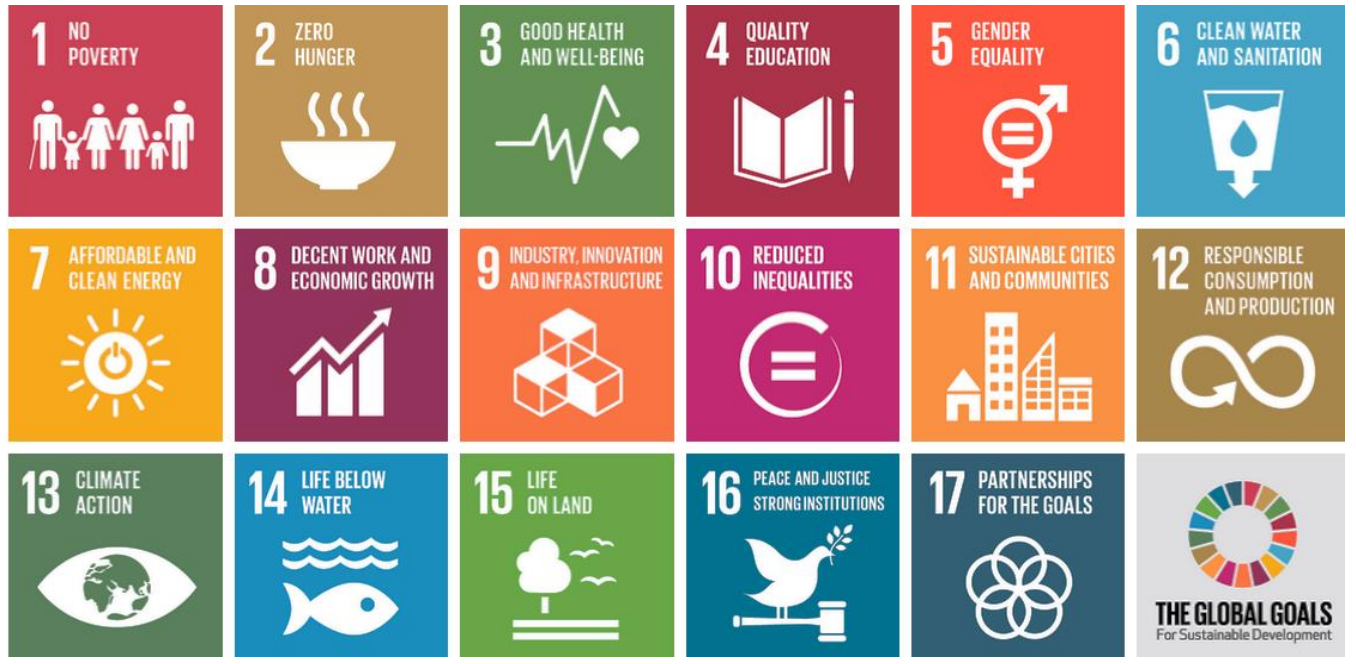

Figure 2. Aspirations of Sustainable Development presented by the UN [14]

These main goals provide sound guidance for counties to work towards a sustainable developed world by 2030. They set out guidelines in terms of resolving problems such as poverty, clean water, environment, equality, energy, and education $[14,15]$.

The agenda of 2030 consists of a summary of goals set out for the world's poorest populations, in terms of resolving the abovementioned issues, which have shown impressive results in the field. However, there are some, who are still against some of these aspirations, and find them in opposition to their unchangeable religious beliefs, political, and to some extent, their financial interests. It is so bizarre, strange and sophisticated to point out why the leadership of Iran strongly rejected such goals for development (Some believe that it is related to the 'Quality Education' and 'Gender Equality' aspirations, showing great similarities to the path of Europe's 'Religious Reform Movement' started by Martin Luther in the 1520s). Satisfying some stakeholders is, somehow, one of the hardest, and in some cases impossible, matters to solve. It is a big question, whether these aspirations are applicable? And if not, what should be done to overcome the related problems?

It was used, previously, to think that oppression and ignorance will only effect the law of all aspects of life, except construction projects. Nonetheless, some experts believe that the rejection of the 2030 agenda for sustainable development by the Iranian leadership proved the other way round. To be more precise, oppression and ignorance do affect sustainable development in terms of project management. This issue should be examined more in future research. 


\subsection{Indicators of Sustainable Development}

Indicators for sustainable development can be measured in existence of permanent sustainability, design and their application in the field, which have been hard to be accepted across the board by all experts in the field. Indicators for sustainable development in different countries can collectively be used to measure sustainable development growth and comparison of such achievements across the world. The United Nations Commission on Sustainable Development (CSD) constructed a sustainability indicator framework for the evaluation of governmental progress towards sustainability. The amount of growth, activities and results of the efforts done by different countries toward this goal, have been scored, rated and published by international institutions annually [16]. For instance, according the SDG Indices obtained by arithmetic mean and geometric average across SDG, published in July 2016, Iran with the score of 58.5 stands in the rank of 79 among 149 of the $193 \mathrm{UN}$ member states (all of them with a population greater than 1 million). Sweden has the first place with the score of 84.5, Australia has the score of 74.5 and the rank of 20 and stands 5 ranks ahead of the united states with the score of 72.7, South Africa with the score of 53.8 has the rank of 99 and finally Central Africa Republic has the lowest score of 26.1 between others [17]. However, this is a general report and does not necessarily mean that the same order is correct in the construction industry. The indicators from an engineering view are in fact different.

It is evident that for a confident comparison of a concept, a unified definition is necessary. This definition needs to include a measurement of divergence from the main goals of the topic. Topic of sustainable development is no exception, an in-depth analysis of these indicators, can paint a comparable picture for sustainable development.

Regarding the aspirations of sustainability and its tree (or four) main pillars, it is possible to define a range of indicators in the construction industry. However, the breadth and complexity of related issues can't be covered without the cooperation of various groups of specialists.

Until now many indicators have been defined in the field of engineering. These indicators are the main elements to address and measure the adaptation of a project with the goals of sustainable development. The footprint of these indicators can be seen in almost all of the buildings standards, codes, rating tools and other products related to this industry [18].

Table 1. The United Nations Commission for Sustainable Development (UNCSD) Theme Indicator Framework and the indicators presented by the ISO 21929 for buildings [19]

\begin{tabular}{|c|c|}
\hline \multicolumn{2}{|c|}{$\begin{array}{c}\text { Core indicators of sustainable development } \\
\text { in general }\end{array}$} \\
\hline \multirow{6}{*}{ 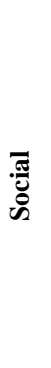 } & Equity \\
\hline & Health \\
\hline & education \\
\hline & Housing \\
\hline & Security \\
\hline & population \\
\hline \multirow{5}{*}{ 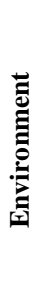 } & Atmosphere \\
\hline & land \\
\hline & Oceans, seas \& coasts \\
\hline & fresh water \\
\hline & Biodiversity \\
\hline \multirow{2}{*}{ 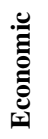 } & Economic structure \\
\hline & Consumption \& production patterns \\
\hline \multirow{2}{*}{ 预 } & institutional frame work \\
\hline & institutional Capacity \\
\hline
\end{tabular}

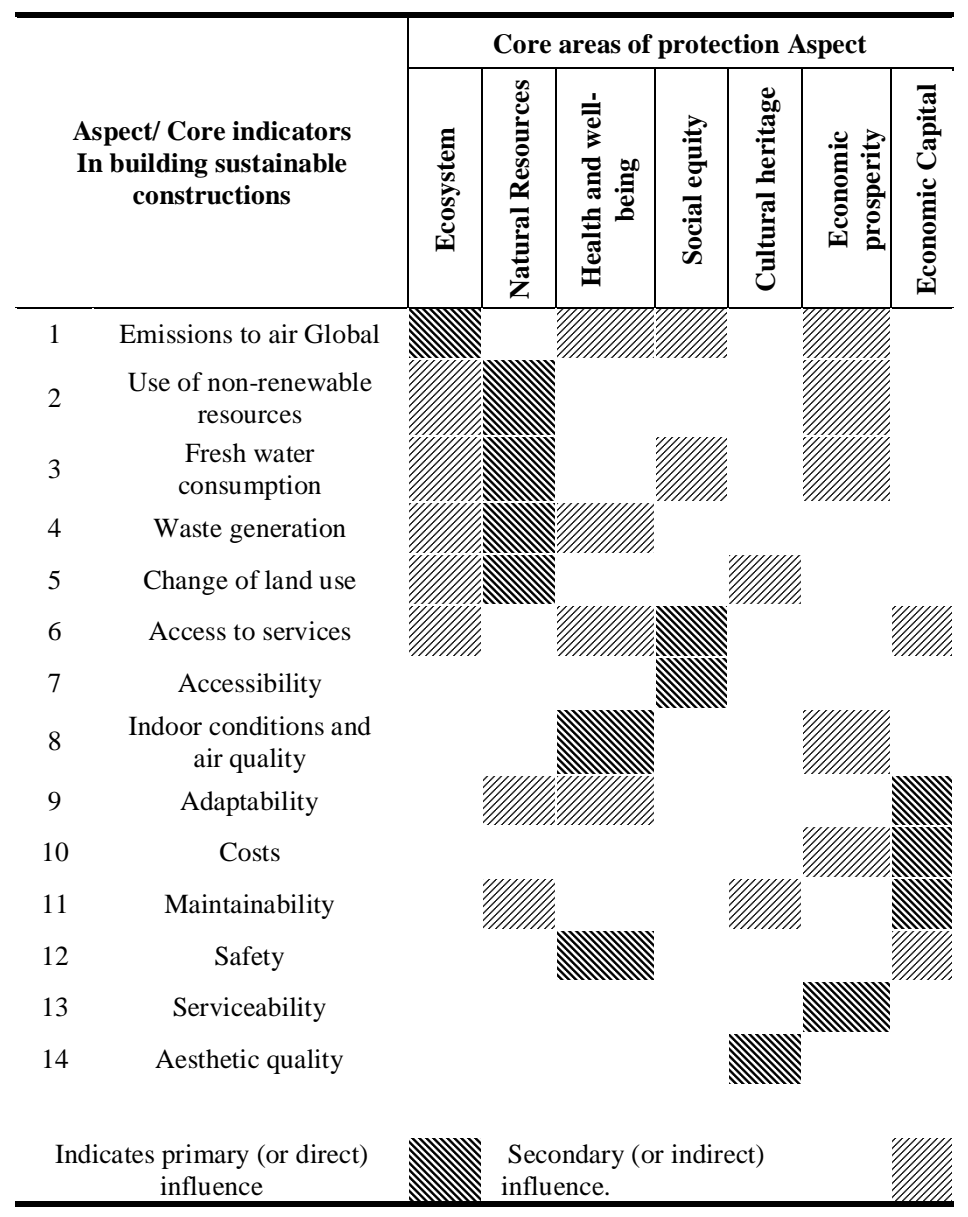


In fact, different indicators have different Core areas of protections. For instance, regarding the ISO standards Ecosystem, Natural Resources, health and well-being, social equity, cultural heritage, economic prosperity and economic capital are the seven core protection areas in building industry[19]. Table 1 shows the general core indicators of sustainable development which is divided between the four pillars of sustainable development, and the core indicators presented by the ISO 21929 standard for sustainable construction. In addition to the presented table there are several other indicators published by different organizations such as the Sustainable Development Solutions Network (SDSN) which have done a great job on monitoring the growth and activities of different countries.

Unfortunately, there is no unified code or standard in Iran directly related to sustainable constructions for addressing the indicators. At the moment, several researches have been conducted in Iranian academic centres, but still no significant practical steps have been taken by a governmental or non-governmental organizations to fill the gap between Scientific Institutions theories and practice in the Industrial centers.

\subsection{Sustainable Development in the Field of Construction Engineering}

Sustainable construction projects affect various stakeholders with different social, environmental and economic interests[20]. Many experts in variety of field and different backgrounds have jumped on the bandwagon to define what it means to be sustainable? They have tried to identify the criteria which should be looked into to inform them of the progress they have made.

In construction industries, the main focus of sustainable development is to create designs which encompass both short term goals of the project and long terms goals of operational systems with respect to sustaining natural resources and the environment. Sustainability in the construction industry is reflected in comprehensive view on the industry in benefits of innovative technologies and utilization of nature in betterment and improvement of the construction projects [9].

Briefly, sustainable development in the construction industry can be divided into two main groups as follows.

A) Green Buildings: the concept of sustainable development is present in all steps of construction, from the initial idea to the final execution of it [21]. According to the United States Environmental Protection Agency (U.S.EPA) "Green building is the practice of creating structures and using processes that are environmentally responsible and resource-efficient throughout a building's life-cycle from siting to design, construction, operation, maintenance, renovation and deconstruction". It can be argued that green structures (buildings) are in essence sustainable development in the field of engineering. The purpose of erection of green structures is the creation of clean and usable environment for the benefits of humanity. This process can be achieved by utilizing and considering resources such as water, soil, energy, recycled and non-recycled materials as core factors in decision making [22].

B) Infrastructures: the Australian Green Infrastructure Council (AGIC) defines Infrastructure as transport (roads and bridges, bus and cycle ways, footpaths, railways), water (sewage and drainage, water storage and supply), energy (transmission and distribution) and communication (transmission and distribution) among others [23]. The benefits of construction industry by considering the size and amount of resources used by the industry, is common knowledge. There have been many publications with regards to Infrastructures regulations in municipal, national and international arenas. With no doubt the topics and actions related to infrastructure matters should be also considered from all points of views.

\subsection{Influence of Building Regulations on Green Buildings}

From 1990 up to now, most of the developed countries have already begun to implement the sustainability policy in their countries and made new regulations to change the conventionally practiced administrative patterns in construction sector [22]. Obviously, regulations and rules have changed the way buildings are implemented. It is a global belief that for avoiding future legal and technical problems, mandatory and voluntary regulations should be enacted and then by priority considered for decision makers in less developed countries.

In the absence of direct green buildings standards in Iran, this question remains unanswered, Weather Iranian policies are in line with the international standards and regulations or going to the opposite direction?" This research has tried to find factors that could help the Iranian construction industry to get in line with international organizations for the sake of a sustainable growth and development.

\subsection{Green Building Councils and Their Role}

As a result of increasing global awareness and for the sake of enabling people to thrive both today and tomorrow, governments started to take action on defining mandatory and voluntary regulations. Many countries have taken some significant steps through formation of organizations and institutions for mutual advice, assistance, and cooperation in helping to shape and implement policy, laws, and regulations for more sustainable forms of development in the 
construction industry. In fact, this was a result of a global common concerns and one of the purposes of the World Commission on Environment and Development in increasing cooperation with Industry for the benefits of all generations [5].

\section{A) World Green Building Council (GBC)}

The WGBS is a network of Green Building Councils all around the world. The WGBC is committed to "Limit global temperature rises to 2 degrees Celsius; Reduce the building and construction sector's $\mathrm{CO} 2$ emissions by 84 Gigatonnes and to ensure all buildings are net zero emissions." By 2050 [24].

A survey of member organizations of the World Green Building Council shows that they pursue a wide range of objectives by using a similarly disperse set of activities [25]. Although every reign has its own principle and regulation on green construction, an international organization such as the WGBC can play a crucial role in sharing experiences.

\section{B) Green Building Councils (GBC) Around the World}

Based on the definition given by the WGBC, "GBC is a national non-profit, non-government organization which is part of a global network recognized by the World Green Building Council". As it can be seen from Figure 3 and with considering the number of countries with Green Building Councils [24] (Table 2), it seems that many countries in Asia and African still haven't established institutions supporting green buildings.

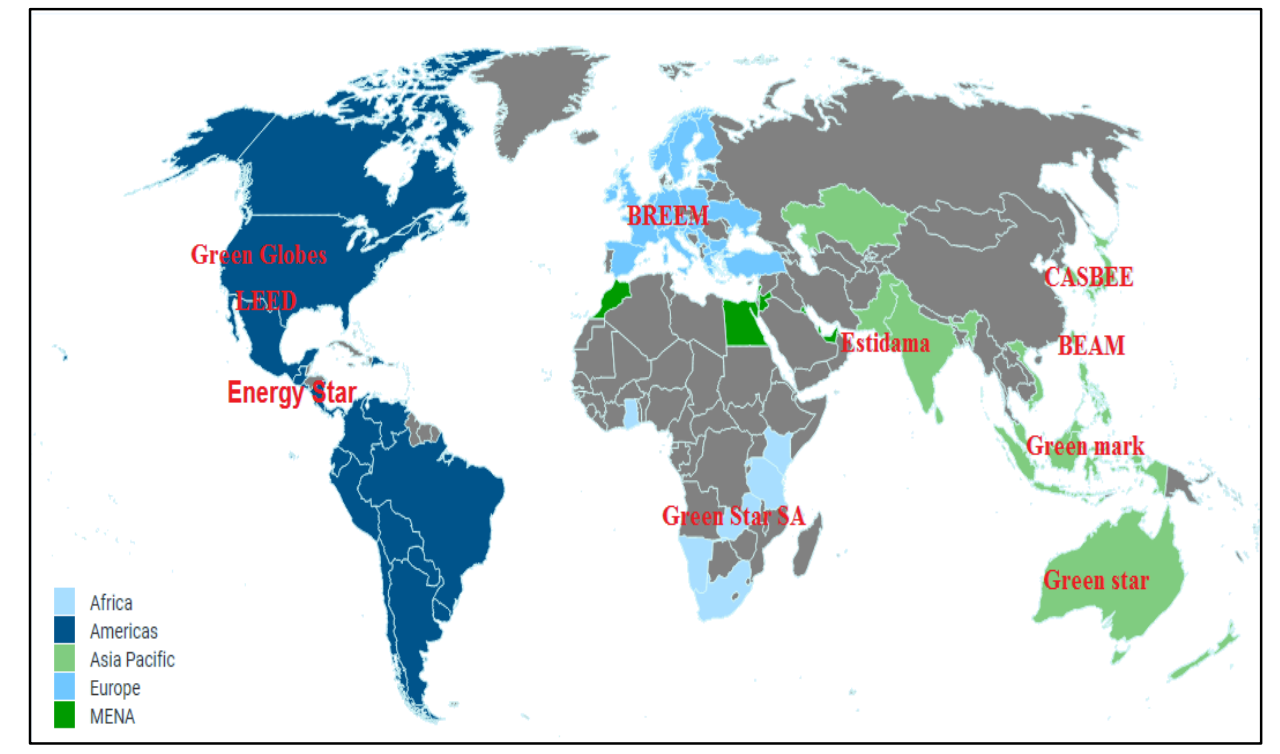

Figure 3. Countries with green building councils around the world [24]

Such councils have published Green building certification systems and rating tools (Sustainability Reporting Tools (SRTs)) and have had a role in defining green building standards regarding the circumstances and priorities of their own countries. These certifications aim to consider sustainable performance of building itself and, in some cases, on its surrounding environment. In fact, these standards with the help of their defined indicators, give us a clear view of the progress we have made in our related field towards sustainability.

Weighting determinations are actually based on expert judgment of authorized professionals and available data analysis, which could be categorized as follows [26]:

- Simple additive such as LEED, Green Globes, Green Mark

- Pre-weighted credits such as BREEAM, DGNB, Green Star

- Weighing after scoring such as SBtool

- Others such as CASBEE and HQE

It is said that the rating tools are a major part of the green building assessment process. It demonstrates the result of calculation and decision tools. It also includes many criteria in different categories. Table. 3 shows some of these Rating Tools [27]. 
Table 2. Countries with green building councils per region [24] (Countries that can be of help by experience sharing)

\begin{tabular}{|c|c|c|c|c|c|}
\hline No. & Africa & Americas & Asia-Pacific & Europe & Mena \\
\hline 1 & Ghana & Argentina & Australia & Austria & Bahrain \\
\hline 2 & Kenya & Bolivia & Hong Kong & Bulgaria & Egypt \\
\hline 3 & Mauritius & Brazil & India & Croatia & Emirates \\
\hline 4 & Namibia & Canada & Indonesia & Finland & Jordan \\
\hline 5 & Rwanda & Chile & Japan & France & Kuwait \\
\hline 6 & South Africa & Colombia & Kazakhstan & Germany & Lebanon \\
\hline 7 & Tanzania & Costa Rica & Korea & Greece & Morocco \\
\hline 8 & Zambia & Ecuador & Malaysia & Hungary & Palestine \\
\hline 9 & & El Salvador & New Zealand & Ireland & Qatar \\
\hline 10 & & Guatemala & Pakistan & Italy & \\
\hline 11 & & Mexico & Philippines & Latvia & \\
\hline 12 & & Nicaragua & Singapore & Luxembourg & \\
\hline 13 & & Panama & Sri Lanka & Macedonia & \\
\hline 14 & & Paraguay & Taiwan & Montenegro & \\
\hline 15 & & Peru & Vietnam & Netherlands & \\
\hline 16 & & Trinidad \& Tobago & & Norway & \\
\hline 17 & & United States & & Poland & \\
\hline 18 & & Uruguay & & Serbia & \\
\hline 19 & & Venezuela & & Slovenia & \\
\hline 20 & & & & Spain & \\
\hline 21 & & & & Sweden & \\
\hline 22 & & & & Switzerland & \\
\hline 23 & & & & Turkey & \\
\hline 24 & & & & Ukraine & \\
\hline 25 & & & & United Kingdom & \\
\hline SUM & 8 & 19 & 15 & 25 & 9 \\
\hline
\end{tabular}

Anyway, the technical way or scientific approach for organizing a rating tool is not a priority for this paper. The vital issue is the necessity for a mandatory standards or tools to guaranty the ability to fulfil the goals of sustainable development.

Table 3. Eleven sample of rating tools

\begin{tabular}{cccc}
\hline Rating Tool & Year & Developer & Country \\
\hline BREEAM & 1990 & BRE & UK \\
HQE & 1994 & HQE Association & France \\
SBtool & 1995 & iiSBE & International \\
LEED U.S & 1998 & USGBC & U.S \\
Green Globes & 2000 & GBI & Canada \& US \\
CASBEE & 2001 & JaGBC & Japan \\
LEED Canada & 2002 & CaGBC & Canada \\
Green Star & 2002 & GBCA & Australia \\
Green Mark & 2005 & BCA & Singapore \\
DGNB & 2007 & DGNB & Germany \\
Green Star SA & 2014 & GBCSA & South Africa \\
\hline
\end{tabular}

\subsection{Standards and Their Role}

According to the CEN-CENELEC Management Centre (CCMC) Standards provide people and organizations with a basis for mutual understanding, and are used as tools to facilitate communication, measurement, commerce and manufacturing. It should be noticed that rating tools for green construction solely shouldn't be recognized as a standard. 
In fact, they are a tools designed to assess the evaluation of a building from social, environmental and economic aspects according to the related standards. Regarding the principles and aspirations of sustainability, several standards are available such as.

- ISO Standards (international standard Organization),

- IGCC (International Green Construction Code),

- ASHRAE (American Society of Heating, Refrigerating and Air-Conditioning Engineers),

- ASTM (American Society for Testing and Materials),

- CSA (Canadian Standards Association),

- BSI (British Standards Institution),

- SANS (South African National Standard),

- Australian NCC (National construction code)

- INBR (Iran National Building Regulations).

However, different standards in different areas face different problems. For instance, some say that the variety of the local standards confuses the users. As a result of this problem, at country level, it's better to amalgamate most of evaluation standards for different buildings into one uniform standard [28], some institutions announce that their code or standards is not suitable for legal reference [29], Some other argue why shouldn't the green building standards be imperative? Or why shouldn't constructing green be compulsory?

Beside the arguments upon the weakness of the existing standards, the benefits of them are undeniable. According the United Nations Industrial Development Organization (UNIDO) and from an engineering view the benefits of standardization can be categorized in four different sectors of society;

For engineering construction, standards:

- Rationalizing the construction process.

- Eliminating or reducing wasteful material or labour during the life cycle of the project.

- Reducing inventories of both raw material and finished products.

- Reducing the cost of implementation and maintenance of buildings.

For customers, standards:

- Assuring the quality of the building or construction and the services received. Providing better value for money.

- Are there any conveniences for settling disputes, if any, with what suppliers?

For traders, standards:

- Providing a workable basis for acceptance or rejection of a specific building.

- Minimizing delays, correspondence, etc.,

For technologists, standards:

- Providing starting points for research and development for further improvement in construction industry.

The primary aims of the standards are as fallow [30]:

1. Fitness for purpose: Fitness for purpose is the ability of the construction, and its process or its services to fulfil the defined purpose under specific conditions.

2. Interchangeability: The suitability of the building to fulfil a relevant requirement is called interchangeability.

3. Variety reduction: Variety reduction is one of the most important aims of standardization in building sector, for the selection, inter alia, of the optimum number of sizes, ratings, grades, compositions and practices to meet prevailing needs.

4. Compatibility: One of the aims of standardization is compatibility, namely, suitability of processes, products or services to be, used together under specific conditions to fulfil the relevant requirements, without causing unnecessary interaction.

5. Guarding against factors that affect the health and safety of the users.

6. Environmental protection 
7. Better utilization of resources

8. Better communication and understanding

9. Transfer of technology

10. Removal of trade barriers

\subsection{Other Approaches for Sustainability}

Every developing step starts from a basic idea or a need which needs to be satisfied. This process is a cycle of four step management method composed of Planning, Doing, Checking and an Adjusting activities well known as the "Deming Cycle". Although, any activity with respect to sustainability is worthless, without applying the principles of the "Deming cycle", due to the excessively large subject matter, in this paper we did not concentrate on the checking and adjusting fazes. Beside the activities such as formation of organizations Such as Green Building councils and drafting of green construction standard, regulations and rating (or evaluating) tools, the followings are some of the methods used worldwide:

- Deployment of Sustainable Technologies in project development: many researches have addressed and documented many green technologies. A check list of these technologies has been summarized by X. Zhang [31]. Solar heating; bio-fuelled combined heat and power (CHP); heat recovery ventilator Radiant thermal slab; Green roof and roof garden; Waste management technology; waste classification and recycling technologies and Prefabricated concrete technology and technologies related to the use of renewable resources are great samples of these technologies which are used by developed countries in the implementation of their constructions.

- Establishing Educational Policies: planning for a sustainable society and sustainable industry starts from education. How can it be expected to have green constructions while mostly don't have a clue of this concept and its criteria? it is a fact that "education is a decisive factor of change" and known as a "soft power" for sustainable development $[32,33]$.

- Utilization of international laws as means to promote sustainable development: Law can make a variety of key contributions in fostering sustainability [34]. In this regard, a lot of international agreements have been approved. Most of these agreements are legally binding for those who have ratified them.

- With no doubt, there are several other samples of efforts done in different fields such as environmental and economic issues which can be a topic to other articles.

\subsection{Example of Successful Green Construction Projects}

There are several great samples of engineering efforts in the field of sustainable construction. Each year the American Institute of Architects (AIA) Committee on the Environment (COTE) announces the top projects that have surpassed rigorous thresholds in integration, energy use, water conservation and wellness benchmarks. The awarded projects are not only sustainable, but also contribute to the surrounding neighbourhood. The Albion District Library in Toronto, Georgia Tech Engineered Bio Systems Building in Atlanta, Mundo Verde at Cook Campus in Washington, D.C. and Nancy and Stephen Grand Family House in San Francisco were the winner of this award in 2018.

The reason why these buildings were awarded can give a wide vision to engineers from the very first stage of designing process through the life cycle of a project. According to the jury of AIA, the characteristic of these buildings can be summarized as, demonstrating the immediate positive impact of good design, weaving a large array of active and passive strategies, reusing the rainwater, cost-efficiency, quality of the calm, light-filled interior spaces for occupants, low-energy usage, a healthy interior environment and site-specific analysis.

\section{Methodology}

Due to the vast nature of the topic of sustainable development, not all components and challenges facing sustainable development can be studied. Therefore, this paper attempts to focus on the importance of coordination and integration of approaches in the construction industry.

This article is a review on the concept, components, dimensions, indicators, aspirations of sustainable development. It also gives information about the efforts done in Iran and tries to make a brief comparison between Iranian and some other international efforts to meet the criteria of sustainable development from an engineering and legal point of view.

To allow new approaches and ideas to be brought up during this research a specific method of research was needed. With the help of a semi structured interview done, the most important practical approaches from the Iranian experts point of view have been expressed and sorted regarding their importance. As the issue of sustainable development is very new for most of the engineers, managers and lawyers in Iran and regarding difficulties for accessing the right population, it was decided to use a snowball research method. By this method 17, law, environment, management and 
engineering university professors and high qualified experts where interviewed (6 law professors, 1 environment professor, 3 management professors and 7 engineering experts).

\subsection{Snowball Researching Method}

Many questioners have been designed by different researches, questions have been asked from different people with no or few knowledge about a specific matter. Maybe the researchers could come to some quantities statistics and consider the gained result as a good result. But, in our case the authors mostly believed that not all engineers, managers or lawyers have enough information to help us to find the elements needed to accomplish the goals of sustainability in the building sector. Hence, a different researching terminology was needed to cope with the situation. The "snowball researching method" is the methodology used in this paper.

The goal of Snowball Method is to share the knowledge and experiences to build best practice in evidence based strategic planning. The approach is to agree a means to measure activities across the entire spectrum of research [35]. The Snowball method is used in cases that identifying the right knowledgeable population is difficult. Many factors can result into this issue. But in this article the main factor was about the lack of experts with experiences in the issue of sustainable buildings and the supportive law.

The snowball researching method implies the identification of an initial set of respondents who will be interviewed and asked to recommend potential subjects who share similar characteristics and who are relevant for the purpose of the subject survey [36]. In this paper a discriminative exponential method was used which has been shown in Figure 4. Regarding the specific researching chosen method. The respondents were asked to name all the experts they know within the target population of the survey and randomly select a certain number of experts from the referrals offered by each respondent.

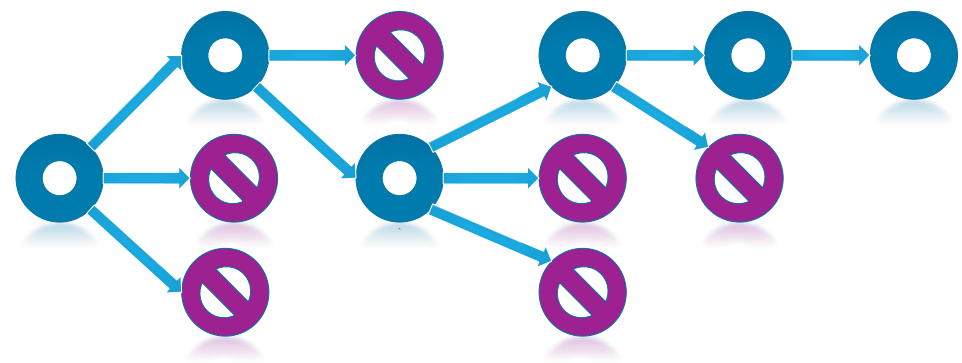

Figure 4. Graphic representation of the discriminative exponential version of the "snowball" method [36]

Although, a vast range of answers were mentioned after each interview, due to the repeating of the recommended elements mentioned by the experts, after 17 interviews, the researchers were satisfied that subsequent rounds of interviews would not bring additional relevant recommendations.

Interviewing different people may result into same answers but mainly the way respondents express their point of view may differ. In order to insure that the interviewer has not misunderstood or misinterpreted the main idea of each respondent after collecting and analysing the answers, the results were shown to the experts and asked whether they exactly meant what was understood by the researcher? This process also allowed the respondents to re-evaluate their views according to the views of others. Finally, a list of different suggestions was prepared. Figure 5 illustrates the process and methodology of this article.

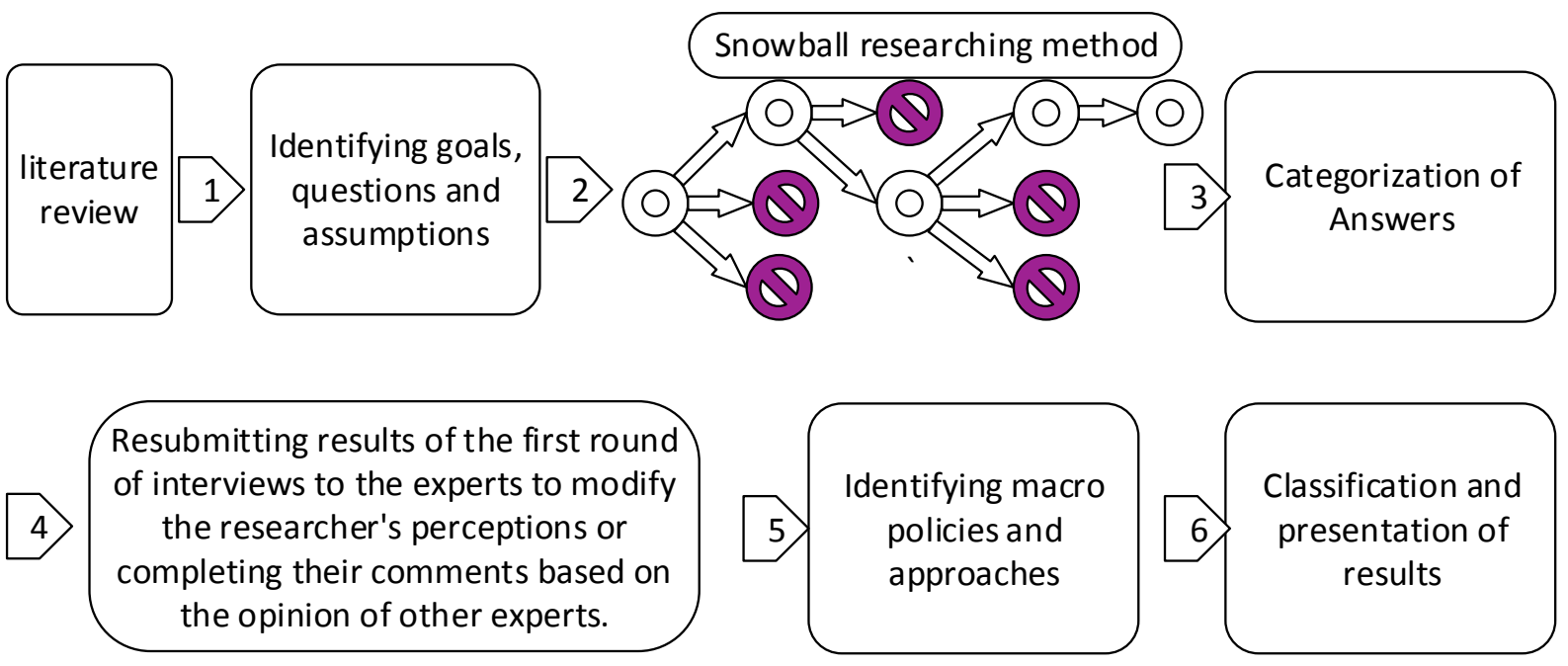

Figure 5. Process and methodology 
Considering the method used to find the best available approaches needed for Iran and as the researchers were knowledgeable that they had chosen the right expert to interview, the respondents were asked to give a rate to each suggestion from 1 to 5 regarding the important of each practical approach. $(1=$ low, $2=$ neutral, $3=$ high, $4=$ very high, $5=$ extremely high).

The practical approaches with an average rate of less than 3 were crossed out and only the important factors were arranged by their importance. By this method 11 different practical approaches were selected and 8 others were crossed out.

\subsection{The External and Internal Factors}

What current and impending internal and external factors will affect the aims of sustainability in construction industry? A question that can tell us which path should we chose in order to achieve success in a project. With the help of the PESTLE method identifying the impediments and factors impacting the aspects of sustainability in the sector of engineering would be possible.

PESTEL is a cost and time efficient mean for highlighting key issues relating to the context of a project or initiative which, if not identified and addressed, could critically affect the chances of success. It also offers the benefit of framing these issues in a way that is easy for participants to understand and discuss [37].

In this research highlighting the issues in generalized categories of strengths, weaknesses, opportunities and threats was necessary. The PESTLE analysis technique mainly helps to create a logical problem breakdown structure[38]. This technique classifies issues as political (P) economic (E), social (S), Technological (T), legal (L) and environmental (E) [39]. In fact, the six PESTLE factors used were trying to find the impact of the followings;

- Political Factors: including pressures and opportunities brought by political institutions and the degree of the impact of government policies on sustainability.

- Economic Factors: including economic structures and to what extent the economy impacts decisions can influence the trend for sustainable buildings.

- Social Factors: including cultural aspects, attitudes, beliefs, that will affect the demand for a sustainable construction and how it impacts the goal.

- Technological Factors: including technological aspects, innovations, barriers and incentives, and to what extent these impact the goals of creating a sustainable environment.

- Legal Factors: laws, regulation and legislation that will affect the way of operation in the engineering sector.

- Environmental Factors: ecological and environmental aspects that will affect the demand for a green construction.

In this research the authors have been focusing on one main question, and that was to find the missing parts needed to achieve sustainable development (and the impediments of this area) in Iran regarding the construction industry. During the semi interviews done, the authors have considered the six above issues to illustrate the best practical approach toward a sustainable construction in Iran. And in cases that the respondents did not considered all the issues explained in the PESTLE approach they were indirectly asked to give their idea about it. In addition, we did not insist the respondents to give a specific answer to a specific question.

\section{Sustainable Development in Iranian Construction Industries}

Mere increase in knowledge level and technical skills and general changes in all fields such as economics, social, political, civil and environmental is without merit, if these elements cannot be applied in practice and they are not used in the proper process level. A concrete change demands applicable and/or preventing tactics with regards to sustainable development. In recent years there has been a great deal of ideas around the issue of sustainable development in Iran, however there has been a few active executions of such ideas. Now a day, there is a wide need to identify the precedents preventing the effective execution of sustainable development from the legal point of view. That is to say, beside the technical issues, in order to bring sustainability to the construction industry, this idea has to be considered from the legal point of view.

The goals of the private sector revolve mainly around cost and profit analyses. Furthermore, the governmental demands consider both financial gain as well as obtaining of benefits for the sake of the society. It is obvious that social, cultural and environmental interests bear a heavy price tag with a low financial return. Naturally the private sector's reception of this matter will be lower than that of the government's. Therefore, proactive measures are necessary in order to prevent short-term gains of private sector at the expense of national disasters in the not so distant future. Raising mass awareness of the people is an evident and distinctive step towards achievement of sustainable development, but one cannot overlook the effect of the binding regulation which are enacted by the legislative power. It is because, without 
the obligatory power of law, the constructive sectors do not have any incentive to design and implement their expensive constructions for the benefit of the society. In other words, from the economic point of view, their interest would not be satisfied.

Green designs that follow environmental principles and try to reduce the consumption of energy and resources should be based on the surrounding's potentials, stakeholder needs, appropriate site selection, recyclable materials and longterm economic feasibility. The international guidelines which provided such regulations, are usually costly and lack financial motive for Iranian contractors and developers. The contractors expect the return of their investment as soon as possible. The risk of non-returning of the capital is extremely high for them. The result of a late returning of the capital and expenditures is, indeed, a reduction in the incentives of the contractors to invest. The domestic investors regularly do not approach such ventures because of the high risks and pessimism exists for the return of their investment. Therefore, the contractors should be given a guaranty for the return of their money to persuade them to implement the necessary regulations with more cost and expenditures. Consequently, investors and key players of the construction industry should be convinced, incentivized, and ultimately obliged to follow the proper regulations to build their constructions (buildings) according to environmental priorities and protection of national resources.

Furthermore, it seems that a reasonable agreement among Iranian policymakers can result into a comprehensive action and a consensus of defining a borderline for the amount of exploitation of natural resources. With no doubt the power of law and legislation can be a great help to prevent national and international catastrophes caused by unwise human activities.

\subsection{Steps Taken in Iran}

From a theoretical view, Iranian researchers have made a great deal of researches about sustainable development in different courses. There are many samples of different conferences about the topic of sustainability during the last 8 years in Iran. However, the practical steps taken are in no way proportionate to the efforts of the academic community. However, the following are some of the efforts done in Iran for the sake of a sustainable country;

- Providing the standard rules such as: air quality and industrial pollution (approved 18/11/2000).

- Elaboration of several environmental impact assessment rules resulting in different environmental reports.

- Providing national rules related to construction: In 1991, the first version of Iranian building codes was compiled aiming to enhance the energy saving of buildings. Section 19 of Iranian National Building Regulations (Issue 19 INBR) is the only mandatory references that addresses some of the basic important energy saving methods in building sector.

- Codification of the Guidelines for Iranian Strategic Environmental Assessment (SEA) of governmental development plans in 2016.

- Tehran municipal rules related to the mega and small projects: This regulation obliges the council of the city (municipal) to respect the required environmental feasibility assessments for large-scale projects and environmental supplemental studies for small projects. Tehran Municipality Environment and Sustainable Development Headquarters has been asked to apply these rules and regulations. Many large-scale urban projects such as the Persian Gulf Martyr's Lake, Sadr Multi-Level Highway, Niyayesh Tunnel, and Tehran's Bird Sanctuary have been completed by Tehran municipality. The rules and regulations of eco-friendly assessments have been applied and executed, in those projects.

- Launching a national strategic plan in 2017 aiming to help the country to adapt and mitigate to risks from climate changes. This plan, was developed in line of the Kyoto Protocol on reducing greenhouse gas emissions and the Paris Agreement for combating climate changes.

- On 19 March 2017, the "Law on the Sixth Five-Year Economic, Cultural, and Social Development Plan for 13961400 (2017 - 2021)" was approved by the Iranian Parliament. The "Sixth Development Plan" sets out the goals and objectives to be achieved by Iran over the next five years with a stronger emphasis on sustainable development by decision-makers. Fortunately, unlike the previous Five-Year development plans a growing trend can be seen towards this plan for having a sustainable country (Lack of attention to sustainability in the last 5 Iranian national development plan has been a topic to other researches [40].

\subsection{Recommendations for Sustainable Development in Iran}

To identify what factors and prerequisites should be considered, in Iran, to have a sustainable structure, using the snowball research method, 17 qualified professionals available were interviewed. Mostly expressing that Iran has remained in the era of speaking, reviewing and reporting and a significant practical movement is needed. This paper is not denying the great work achieved in Iran in terms of reducing poverty, and some other issues, which are somehow related to sustainable development, but which are insignificant when compared to the current needs. The construction 
sector, which is and always has been one of the most profitable industries in Iran is not an exception. Some believe that financial problems are the greatest impediments to green construction.

To determine if a building or a structure is green or not the following six challenging matters should be considered (Figure 5). Considering all steps starting from legal obligations until marketing analysis, several factors including 'cost and benefit' analysis and financial matters should be considered. Experts interviewed, believed that without the consideration of these six elements, the goal of sustainability cannot be achieved in construction industries. Currently, there are very few examples, which have considered all these elements in the Iranian green building industry.

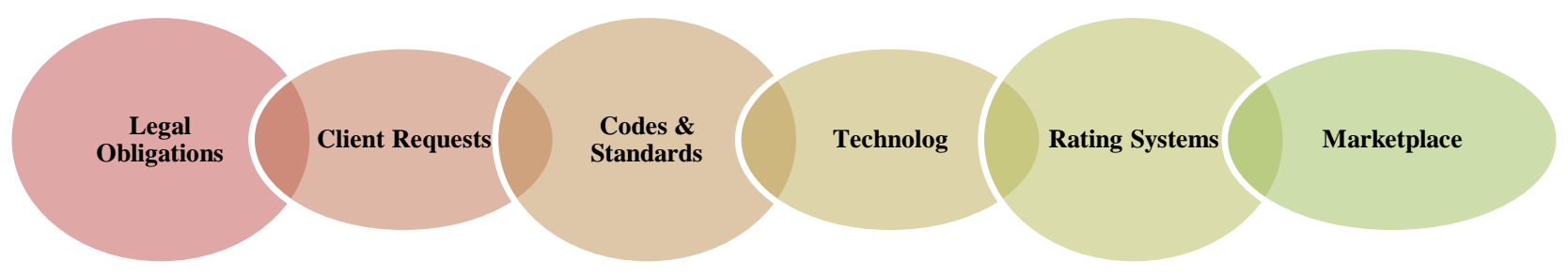

Figure 5. Elements determining green buildings

Generally, Iranian decision makers believe that there are major challenges more important than constructing green. Moreover, there is not a wide trend toward this issue among managers and engineers, and if there was, there is no guarantee for investing in this field. In other words, the existing disorder in the construction industry and the unclear marketplace together causes fear for financers to adopt green building.

The results emphasize that Iran needs a new development vision. 11 of the most important recommendations have been summarized and presented in Table 4 courtesy of professionals and experts familiar with the current Iranian situation. The mean score (MS) is bases upon responses to a five-point scale, and ranges between 1.0 and 5.0.

Table 4. Practical approaches Recommended for implementation of sustainable construction in Iran

\begin{tabular}{|c|c|c|}
\hline No. & Recommendation & MS \\
\hline 1 & $\begin{array}{l}\text { Increasing the global awareness of the people as to the effects of the implementation of different constructions on the society, in } \\
\text { order to gain their full support for the sustainable development plans. This global awareness will result into new demands, } \\
\text { generation of new courses and new educations will be needed in construction field in the not so far future. }\end{array}$ & 4.38 \\
\hline 2 & $\begin{array}{l}\text { Making direct compulsory rules and regulations related to the construction by the legislative and administrative power, and } \\
\text { applying appropriate penalties to actions which contradict the goals of sustainable development. In should be noticed that green } \\
\text { construction is a matter beyond environmental issues and cannot by addressed only energy saving codes/rules or by strategic } \\
\text { environmental assessment (SEA) tools or polices. The law makers should consider all the } 3 \text { (or } 4 \text { ) pillars of sustainable } \\
\text { development in this specific sector. }\end{array}$ & 4.31 \\
\hline 3 & $\begin{array}{l}\text { Cooperation between law makers and engineers and managers: The aim of each course is to some extent different from the aim of } \\
\text { the others. For instance, the aims of the engineering and the law are not necessarily coincide. Although, different courses have the } \\
\text { same general goal, their different ways of approaching toward sustainability leads to a lot of tensions among the managers, } \\
\text { lawyers and engineers. In order to reach to a similar approach and similar understanding, for similar goals, their co-operation is } \\
\text { urgently needed. }\end{array}$ & 4.00 \\
\hline 4 & $\begin{array}{l}\text { Identification of the social and environmental indicators and factors for the application of national, territorial and local } \\
\text { construction strategies. }\end{array}$ & 4.00 \\
\hline 5 & $\begin{array}{l}\text { Respecting the "Costs and Benefits" rule for the sake of financers, constructors and the consumers with regard to a new risk } \\
\text { sharing policy. The "Business as Usual" approach will no longer work and a new business vision is needed. }\end{array}$ & 3.97 \\
\hline 6 & $\begin{array}{l}\text { Considering and applying the results of future (futurology) and feasibility studies regarding client requests and future resources } \\
\text { for the construction of green buildings. }\end{array}$ & 3.94 \\
\hline 7 & $\begin{array}{l}\text { Taking the views of the private and general stakeholders and the interested parties in to account, in order to prevent the future } \\
\text { intervention of the stakeholders and influential real and legal persons. }\end{array}$ & 3.91 \\
\hline 8 & $\begin{array}{l}\text { Co-ordination and co-operation between governmental and administrative sectors from one side, and the private sectors from the } \\
\text { other, for providing common constructing rules related to economy, technology, policy and environmental aims. In fact creation } \\
\text { of sustainable constructions and infrastructures and in general a sustainable society is a public duty. }\end{array}$ & 3.78 \\
\hline 9 & $\begin{array}{l}\text { Studying the long term effects of constructions on the environment for the protection, reduction, and mitigation of the contingent } \\
\text { damages and risks to the present and next generation. }\end{array}$ & 3.78 \\
\hline 10 & $\begin{array}{l}\text { Full efforts for finding the affairs which positively or negatively influences the protection or the risks to the national resources. } \\
\text { Codification of a new and up to dated strategy, for solid waste and wastewater treatment, energy saving policy and use of recycled } \\
\text { materials in construction industry. }\end{array}$ & 3.75 \\
\hline 11 & $\begin{array}{l}\text { Increasing the co-operation with the international organizations (including; States, UN and World Green Building Council) for the } \\
\text { protection of mutual interest in a global scale. Sharing experiences with other developed countries can booster the process of } \\
\text { Iran's sustainability. These co-operations can also result into attraction of foreign direct investment. }\end{array}$ & 3.44 \\
\hline
\end{tabular}




\section{Conclusion}

Several studies have been conducted with respect to sustainable development across various fields in Iran, However, determining or coordinating the relationships between them are unprecedented and undefined. Bridging the gap between management, legal affairs, and the building industry is a key factor in achieving the goals of sustainability. To date, these three areas have not been scrutinized simultaneously to examine their effects on each other. Each player has functioned independently and autonomously, so these are negatively affecting the overall objectives of sustainable development. In this manner, a close working relationship must evidently be established between the industrial and legal sectors. In other words, determining the required legal support for implementing engineering parameters considering a wise way of consuming natural and financial resources and is vitally needed to avoid falling further behind. In addition to the legal backing which could be achieved by the co-operation of different fields the rules of "cost and benefit" for all stakeholders should be respected as well. In this research, the important points related to sustainable development in green construction (buildings) from the view point of Iranian experts are explained. With the help of a 'PESTLE' analysing tool and the 'Snowball' researching method, the top 11 practical approaches needed in Iran were suggested and sorted regarding their importance. The impact of compulsory rules and regulations was acknowledged as the most important factor needed for sustainability in Iran. It is believed that an effective legislation can only be reachable by the co-operation of different disciplines and co-ordination between governmental, administrative sectors and the private sectors. In addition, sharing experiences and knowledge with international institutions such as 'World Green Building Council' and a proper education can accelerate the process of sustainable development in Iranian construction industry. According to the interviews done, the six challenging matters including Legal Obligations, Client Requests, Standards and Codes, Rating Systems and finally the Marketplace should be considered for implementation of a green constructions in Iran.

\section{References}

[1] Avilés, Luis A. "Sustainable Development and Environmental Legal Protection in the European Union: A Model for Mexican Courts to Follow?” Mexican Law Review 6, no. 2 (January 2014): 251-272. doi:10.1016/s1870-0578(16)30014-2.

[2] Declaration, Rio. "Rio declaration on environment and development." (1992).

[3] United Nations, "Sustainable Development. Knowledge Platform (Iran), 2013.

[4] Torvik, R. "Why Do Some Resource-Abundant Countries Succeed While Others Do Not?" Oxford Review of Economic Policy 25, no. 2 (June 1, 2009): 241-256. doi:10.1093/oxrep/grp015.

[5] Keeble, Brian R. “The Brundtland Report: 'Our Common Future.” Medicine and War 4, no. 1 (January 1988): 17-25. doi:10.1080/07488008808408783.

[6] Duran, Dan Cristian, Luminita Maria Gogan, Alin Artene, and Vasile Duran. "The Components of Sustainable Development - A Possible Approach.” Procedia Economics and Finance 26 (2015): 806-811. doi:10.1016/s2212-5671(15)00849-7.

[7] Dobrovolskienè, Nomeda, and Rima Tamošiūnienė. "An Index to Measure Sustainability of a Business Project in the Construction Industry: Lithuanian Case.” Sustainability 8, no. 1 (December 25, 2015): 14. doi:10.3390/su8010014.

[8] Illankoon, I. M. Chethana S., Vivian W. Y. Tam, and Khoa N. Le. "Environmental, Economic, and Social Parameters in International Green Building Rating Tools.” Journal of Professional Issues in Engineering Education and Practice 143, no. 2 (April 2017): 05016010. doi:10.1061/(ASCE)ei.1943-5541.0000313.

[9] Hill, Richard C., and Paul A. Bowen. "Sustainable Construction: Principles and a Framework for Attainment." Construction Management and Economics 15, no. 3 (May 1997): 223-239. doi:10.1080/014461997372971.

[10] Hassan, Abbas M., and Hyowon Lee. "The Paradox of the Sustainable City: Definitions and Examples." Environment, Development and Sustainability 17, no. 6 (November 29, 2014): 1267-1285. doi:10.1007/s10668-014-9604-z.

[11] Intergovernmental Panel on Climate Change, ed. "Summary for Policymakers." Climate Change 2013 - The Physical Science Basis (n.d.): 1-30. doi:10.1017/cbo9781107415324.004.

[12] Nurse, Keith. "Culture as the fourth pillar of sustainable development." Small states: economic review and basic statistics 11 (2006): 28-40.

[13] "Report: Review of Targets for the Sustainable Development Goals: The Science Perspective." Journal of Education for Sustainable Development 9, no. 2 (August 31, 2015): 237-237. doi:10.1177/0973408215600602h.

[14] Group, O.W., Goals, S.D., Group, O.W., Goals, S.D., Goals, D., and Goals, S.D., "Sustainable Development Goals and targets," United Nations, 2015.

[15] Hambrey, J., "The 2030 Agenda and the Sustainable Development Goals: The challenge for aquaculture and Management," ISBN $9789251099285,2017$.

[16] United Nations, "Indicators of Sustainable Development: Guidelines and Methodologies,” ISBN 9789211045772, 2007.

[17] Sachs, Jeffrey, Guido Schmidt-Traub, Christian Kroll, David Durand-Delacre, and Katerina Teksoz. SDG index \& dashboards: A global report. Bertelsmann Stiftung, 2016. 
[18] Singh, Rajesh Kumar, H.R. Murty, S.K. Gupta, and A.K. Dikshit. “An Overview of Sustainability Assessment Methodologies.” Ecological Indicators 9, no. 2 (March 2009): 189-212. doi:10.1016/j.ecolind.2008.05.011.

[19] Standard, I., "INTERNATIONAL STANDARD-ISO 21929-1 Sustainability in building construction — Sustainability indicators Part 1: Framework for the development of indicators and a core set of indicators for buildings Développement," $2011,2011$.

[20] Li, Hongyang, Xiaoling Zhang, S. Thomas Ng, and Martin Skitmore. "Quantifying Stakeholder Influence in Decision/evaluations relating to Sustainable Construction in China - A Delphi Approach.” Journal of Cleaner Production 173 (February 2018): 160-170. doi:10.1016/j.jclepro.2017.04.151.

[21] Zhang, Jian Wen. "Cost, Efficiency and Hygiene - Three Reflections on Green Building." Applied Mechanics and Materials 587-589 (July 2014): 203-207. doi:10.4028/www.scientific.net/amm.587-589.203.

[22] Mohammadi, Sahra, and M. Talat Birgonul. "Preventing Claims in Green Construction Projects through Investigating the Components of Contractual and Legal Risks." Journal of Cleaner Production 139 (December 2016): 1078-1084. doi:10.1016/j.jclepro.2016.08.153.

[23] Infrastructure Australia, “Australian Infrastructure Plan,” ISBN 978-1-925352-07-8, 2016.

[24] World Green Building Council, http://www.worldgbc.org/about-green-building, 2017.

[25] Sedlacek, Sabine, and Gunther Maier. "Can Green Building Councils Serve as Third Party Governance Institutions? An Economic and Institutional Analysis.” Energy Policy 49 (October 2012): 479-487. doi:10.1016/j.enpol.2012.06.049.

[26] Alyami, Saleh H., and Yacine Rezgui. "Sustainable Building Assessment Tool Development Approach.” Sustainable Cities and Society 5 (December 2012): 52-62. doi:10.1016/j.scs.2012.05.004.

[27] Chehrzad, M., S. M. Pooshideh, A. Hosseini, and J. Majrouhi Sardroud. "A Review on Green Building Assessment Tools: Rating, Calculation and Decision-Making.” The Sustainable City XI (July 12, 2016). doi:10.2495/sc160341.

[28] Ye, Ling, Zhijun Cheng, Qingqin Wang, Haiyan Lin, Changqing Lin, and Bin Liu. "Developments of Green Building Standards in China." Renewable Energy 73 (January 2015): 115-122. doi:10.1016/j.renene.2014.05.014.

[29] Board, A.B.C., "NCC 2015 Performance Requirements Extract," 2015.

[30] United Nations, "Role of Standards: A Guide for Small and Medium-sized Enterprises,” Unido, 2006.

[31] Zhang, Xiaoling. "Paradigm Shift Toward Sustainable Commercial Project Development in China." Habitat International 42 (April 2014): 186-192. doi:10.1016/j.habitatint.2013.12.009.

[32] Nikolayevich Sayamov, Yury. "Education as a Global ‘soft Power' for Sustainable Development." Edited by Dr Gilbert Ahamer. Campus-Wide Information Systems 30, no. 5 (November 4, 2013): 346-357. doi:10.1108/cwis-08-2013-0040.

[33] Nasibulina, Anastasia. "Education for Sustainable Development and Environmental Ethics." Procedia - Social and Behavioral Sciences 214 (December 2015): 1077-1082. doi:10.1016/j.sbspro.2015.11.708.

[34] Dernbach, John C., and Joel A. Mintz. "Environmental Laws and Sustainability: An Introduction." Sustainability 3, no. 3 (March 23, 2011): 531-540. doi:10.3390/su3030531.

[35] Colledge, L., "Snowball Metrics Recipe Book," 114, 2014.

[36] Voicu, Mirela-Cristina, and A. Babonea. "Using the snowball method in marketing research on hidden populations." Challenges of the Knowledge Society 1 (2011): 1341-1351.

[37] Unicef, "SWOT and PESTEL," UNICEF KE Toolbox 1-12, 2015.

[38] Forbes, Doug, Simon D. Smith, and Malcolm Horner. "A case-based reasoning approach for selecting risk management techniques." In The Proceedings of 23rd Annual ARCOM Conference, Association of Researchers in Construction Management, pp. 735-744. 2007.

[39] Zalengera, Collen, Richard E. Blanchard, Philip C. Eames, Alnord M. Juma, Maxon L. Chitawo, and Kondwani T. Gondwe. "Overview of the Malawi Energy Situation and A PESTLE Analysis for Sustainable Development of Renewable Energy." Renewable and Sustainable Energy Reviews 38 (October 2014): 335-347. doi:10.1016/j.rser.2014.05.050.

[40] Mahdei, Karim, Mehrdad Pouya, Fatemeh Taheri, Hossein Azadi, and Steven Van Passel. "Sustainability Indicators of Iran's Developmental Plans: Application of the Sustainability Compass Theory." Sustainability 7, no. 11 (November 3, 2015): 1464714660. doi:10.3390/su71114647. 